\title{
Formation of the Education Subjects' Technological Culture Based on the Ethnoaesthetic Values
}

Mikhail G. Kharitonov

Gennady A. Nikitin

Faina P. Kharitonova

Marina B. Kozhanova

Vasiliy P. Kovalev

Tatiana V. Gorbunova

Irina N. Petrova

Chuvash State Pedagogical University named after I.Y. Yakovlev, Cheboksary, Russia

Email: Mgkhar@mail.ru

\section{Doi:10.5901/mjss.2015.v6n2s3p105}

\section{Abstract}

The relevance of the research problem is due to the definition of the leading idea of formation of students' technological culture in the context of the regional component. The article is aimed at revealing the content of this process on the basis of ethnoaesthetic values. The research was based on a set of such mutually reinforcing methods as theoretical, empirical. The main content of the article focuses on the conceptual rationale for ethnoaesthetization of educational space as a substantial basis for forming high students' philosophical worldview through the development of the archaic technologies for materials processing craft as the basis for studying the industrial, modern, high technology, and house culture, and the motive of their acquisition of professional competencies in the institutions of primary, secondary, higher professional education. The results of the research suggest about the importance of ethnoaesthetic values in the formation of motivational, cognitive, activity components of technological culture within the technology education of students in a multicultural region.

Keywords: ethnoaesthetic values, formation of a technological culture, ethnoaesthetic didactics

\section{Introduction}

\subsection{The urgency of the problem}

The existing condition of spiritual instability in the society needs the search for innovations in technological education, directing the attention of scholars to solving the problem of socialization of the process of forming students' technological culture on the basis of ethnoaesthetic values. The social targeting of this concept on the synthesis of scientific and ethnic values is concentrating, primarily, on disclosure of positive integration processes of updating the high school students' technological education, contributing to the development of industriousness, technological, spiritual knowledge, skills, ethnoaesthetic consciousness, a thrifty approach to the matter, creative, project-related thinking, self-reliance, initiative, entrepreneurial attitude, professional mobility, et cetera.

\subsection{The importance of the research problem}

Pedagogical analysis of the system status of high school students' modern technological education has aggravated the problem of finding novelties, designing new developments in the process of forming a technological culture in the framework of the regional components. The problem of designing innovations on the aesthetic values of ethnic culture in the indicated process shall be resolved with reference to the integrability of the general provisions of technology education didactics and the ethnoaesthetic didactics within the local, regional mental peculiarities of preparing young 
people for the working life. Each region differs by ethnoaesthetic specificity of a traditional pedagogical culture; scientifically substantiated in the form of ethnopedagogy (Kharitonov, 2004). Its scientific and pedagogical framework includes elements of ethnoaesthetic values. At the same time the aesthetic values of ethnic pedagogical culture act as didactic tools for forming the education subjects' traditional industriousness and as the content of the work training, national rules of labor education, methods and forms of initiation to the work; the nature and means of aesthetic education in terms of the younger generation beauty ideal.

To ensure the scientifically-based ethno-pedagogical support of the students' technological culture formation process on the basis of the ethnoaesthetic pedagogical components a system approach is required for identifying the values of motivating learning of the subject "Technology", that creates at the stage of the pre-core training (8-9 grades), the core training (10-11 grades), the conditions of independent search activation, and of the future profession selection.

Aesthetic values of the nations, including the Chuvash, scientifically-substantiated in the form of ethnoaesthetics as a phenomenon of the universal human culture, are an indicator to determine the degree of spirituality of the technological culture of not only an individual student, but also of the society, the state as a whole. Ethnoaesthetic values, in conjunction with other traditions, which have been contributing to the development of industriousness for centuries, act as a didactic basis of ensuring the procedural side of researching the system, axiological, person-activity, ethnoaesthetic approaches by way of pedagogical tools. As the theoretic-methodological basis of the conceptual substantiation of the aesthetic life category like the "code" (Kagan, 1998) in the formation of the education subjects' technological culture on the basis of ethnoaesthetics within the Chuvash region, appears to be the historical and socio-cultural analysis of such types of universal culture as mythological, cosmological, anthropological, technological.

\subsection{Ethnoaesthetic values of the Chuvash region in preparation for work life}

The picture of the ancient world of objects seems to be the starting point for designing the pedagogical innovation theory, referring to the initial values of the life activities according to the principle of ethnoaesthetic didactics "A smart man learns from people and teaches the people". Following his logic, the research efforts of students are directed to the identification of the ethnoaesthetics origins in the evolution of technologies as examples of the culture formation in upbringing ethnic groups not from the writing period, but from the pre-writing pedagogy.

In identifying the origins of ethnoaesthetic heritage of educative concepts in primitive society as a part of the technological culture, a cut of local archaeological monuments is carried out, of the Chuvash Volga region "going deep to 60-40 thousand years." The upbringing picture has been considered in ethno-pedagogical interpretation of the mythological culture since the epochs of the Upper Paleolithic, the Mesolithic (XII-V thousand years B.C.), the Neolithic (VI-III thousand years B.C.), the Bronze Age (end of the III-II millennium B.C.): Fatyanovo, Balanovo, Gorodets, Srubna, Abashevo cultures - at the places of studying mounds; the Iron Age (the beginning of the first millennium B.C.); the cultures of the Volga Bulgars (IX XIII century); the Cosmologic culture (XV - the first half of XVIII centuries); the anthropologic ("foreign" schools, "workshop of humanity" of the XVIII century), the technological cultures (XVIII - the beginning of XX centuries) - archival materials about "outreach activities of the Simbirsk County", the Simbirsk Chuvash teachers' school (Kharitonov, 2006), Varaksarskaya Chuvash female labor community. The main purpose of exploring the historical values of ethnoaesthetics - is to teach high school students to feel the link of times between the past, the present and the future, to carry out the dialogue of cultures, because no culture is self-sufficient.

The general principle of conceptual substantiation of the dialogue of cultures, that is, the interchange with the aesthetic values of ethnic culture in the formation of students' technological culture, comes forth the Chuvash folk wisdom "If you look back on your way, there will be new ideas". The scientific provisions of the dialogue of cultures are the theories about the formation of the subjects' continuing education "natural-scientific worldview" (Khotuntsev, 2002), the technological worldview, about the ethnic worldview, the ethnic in the field of aesthetics, the ideas of "ethno-pedagogical pansophy" (Volkov, 2009), the culture of senses.

\subsection{Status of this problem}

The concept of creating a technological culture among students at the pedagogical component of ethnoaesthetics is modeled by ethno-social ideas based on the human-oriented position, contributing to the development of "mind, heart and hand". The system-activity ethnoaesthetic approach is based - on the theoretical provisions of "the Concept of creating a technological culture of the youth in general educational and culturally congruent school of Russia", "the Concept of national educational policy of the Russian Federation", "the Concept of profile education at the senior level of general education", "the Ethno-pedagogical concept", "the Concept of ethno-cultural education in the Russian Federation", "the 
Development of Self-conception and upbringing", "the Concept of methodical system of training a technology and entrepreneurship teacher for the aesthetic upbringing of schoolchildren" and others; - on the experience of the systemic ethno-pedagogization of holistic educational/upbringing process in the Chuvash-German gymnasium of Truckee village, Yadrinskaya national gymnasium, schools of Leninsky district of Cheboksary, Yakutsk national gymnasium, and others.

\subsection{The hypothesis of the research}

The analysis of the pedagogical practice theory within the schoolchildren's technological culture formation, the ethnopedagogization of the teaching/upbringing experience of educational institutions of not only in the Chuvash Republic, but also in other regions of Russia, has shown that the problems associated with the conceptual rationale for creating the technological culture of the education subjects, on the basis of ethno-aesthetic values, to date has been insufficiently studied (Nikitin, 2011). Hence, the hypothesis of this research is based on the assumption that the formation of the continuous education subjects' technological culture on the basis of the ethnoaesthetic values will be effective if: the theoretical and methodological provisions of the ethnoaesthetic approach are substantiated, which integrate the aesthetic, ethno-pedagogical, anthropological, system, axiological, person-focused, activity-based, competence-based approaches; the historical and socio-cultural analysis of universal cultures is carried out, which are marked on the territory of the Chuvash Republic; pansophism of the domestic and foreign philosophical-pedagogic cultures, which will identify the ethnoaesthetics basics, to justify it as a pedagogical component, to determine the methodological guide of culturocentric improvement of the modern system of the education subjects' technological culture formation on the basis of the ethnoaesthetic values; the concept has been developed on the education subjects' technological culture formation in the context of the pedagogical component of ethnoaesthetics, able to focus the educational paths on personality socialization, corresponding to the spiritual needs of the society, the labor market; the substantive provisions of the ethnoaesthetic didactics have been identified, based on a retrospective analysis of ethno-pedagogical, ethnographic, archaeological, archival, field materials, which will allow to specify the structure and criteria of the technological culture development; a comprehensive model of creating a technological culture of the subjects of continuing education has been developed, based on the ethnoaesthetic values, developed on a multiparadigm approach; a procedure for designing the content, the pedagogical conditions has been developed, and the organizational-pedagogical mechanism to ensure the formation of a technological culture among students has been revealed on the basis of ethnoaesthetics.

\section{Materials and Methods}

\subsection{Objectives of the study.}

In the research process a solution to such problems was provided as: 1) development and substantiation of the theoretical and methodological foundations of the ethnoaesthetic approach, facilitating the efficient formation of the education subjects' technological culture ; 2) implementation of the historical and socio-cultural analysis of universal cultures, marked on the territory of the Chuvash Republic, the phenomenon of pansophism of domestic and foreign philosophical-pedagogical cultures with justification of ethnoaesthetics as a pedagogical component; 3) identification of the methodological guide of culturocentric improvement of the existing system of creating students' technological culture in the system of modern education; 4) implementation of a retrospective analysis of ethno-pedagogical, ethnographic, archaeological, archival, field materials to develop basic provisions of ethnoaesthetic didactics; 5) development of the basic provisions of the education subjects' technological culture formation on the basis of ethnoaesthetic values; 6 ) substantiation of an integrated model of creating a technological culture of the education subjects on the basis of ethnoaesthetics, developed on a multiparadigm approach; 7) development of the procedure for designing the content, pedagogical conditions, and disclosure of the organizational and pedagogical mechanism for ensuring the formation of a technological culture among students on the basis of ethnoaesthetics in the education system; 8) identification of criteria for the maturity level of the education subjects' technological culture on the basis of the ethnoaesthetic values.

\subsection{Theoretical and empirical methods}

To test the hypothesis the research was based on a complex of mutually reinforcing methods: 1) theoretical - study and analysis of the theoretical and applied research in the field of technological culture, pedagogics, and ethno-pedagogy; comparative analysis of philosophical, psychological-pedagogical, methodological, culturological, fine art, ethnographic studies, archaeological, ethnoaesthetic materials; systemic-functional analysis of the pedagogical activity of educational 
institutions; scientific synthesis of the actual materials; modeling and abstraction, hindsight analysis, and others; 2) empirical - investigation, collection, systemization of the archive, field materials, monuments of material and spiritual culture; compilation of the many years' teaching experience of the author on the formation of the technology-based culture through ethnoaesthetics in the system of national education "High school - University - Further Vocational Education"; pedagogical observation, questioning, studying the process under investigation; interviewing students, teachers, administration, parents to identify their attitude to the problem of the research; ascertaining and formative experiment, statistical processing of the results.

\subsection{Base of the research}

The experimental base of the research were the municipal educational establishments of comprehensive high schools № 2 in Shumerlya, № 22, № 28, № 49, № 62 in Cheboksary, ethno-pedagogical grades of Kugesskaya comprehensive high school №1 of Cheboksary region in the Chuvash Republic.

\subsection{The stages of the research}

The research was conducted in four interrelated stages.

The first stage - the search-theoretical - was aimed at identifying the problematic field of the research and the degree of its elaboration in pedagogical science; accumulation and substantiation of the methodological framework of the theoretical and empirical research material, for which purpose the data from the archival, field, scientific sources have been collected. The result was the identification of the general regulations, which helped to develop a line of ethnoaesthetics basics, outline the vector for using its didactic components in practice of creating the education subjects' technological culture.

The second stage - the structurally-diagnostic - included the familiarization of the educational institutions' personnel with the terms of implementing this process within the innovative educational activity. The basis of the research was the definition of the pedagogical design aspects, for which purpose a hindsight analysis was conducted on the experience of domestic and foreign schools according to our subject area, a comparative analysis, adjustment of curricula, programs, material resources of the training workshops. According to the research results, the conceptual and categorical, as well as methodological framework has been systematized; the conceptual provisions of creating the technological culture of the subjects of education through ethnoaesthetics have been identified, its criteria have been developed; the regulations for implementing the holistic educational process in the system of national education have been elaborated; the ascertaining experiment was carried out.

The third stage - experimental-prognostic. To ensure it, the adjustment, the substantiation of the basic provisions of the concept of creating a technological culture of the learning youth continued in the context of the pedagogical component of ethnoaesthetics and their publication in mass circulation; according to the stated problem a model was being developed as an integrative mechanism for implementing the components of the ethnoaesthetic didactics and the didactics of technological education in the general education system; its effectiveness was being identified. Within the framework of the system the formative experiment was conducted. The procedural side was supported by a group of creatively working teachers, whose high-quality interaction was provided through the informational training seminars, research-to-practice conferences and technology competitions of different levels. According to the preliminary results of the experimental work, the recommended practices were developed, the training manuals were created.

The fourth stage - analytical-generalizing. At this stage the re-verification of the developed model's efficiency was carried out, the pedagogical conditions of executing the effectiveness of creating the technological culture of the students; the effect of personality socialization formation was identified. The results were tested at the international, Russian-wide, regional and inter-university conferences; were summarized in the monographs, textbooks, publications in leading Russian and inter-regional scientific-educational editions; the scientific and literary report of the research materials was completed.

\subsection{Evaluation criteria}

Evaluation of the ethnoaesthetic values effectiveness in shaping the education subjects' technological culture was performed according to the following components: emotionally-evaluative (ethnoaesthetic consciousness), cognitive (technological worldview, knowledge) and activity (technological abilities, skills, thinking, aesthetics (design), ethics, diligence. The criteria were: a high school student's emotional sphere development level - as an indicator of the degree 
of development, encouraging (motivating) to activity; the level of cognitive - as an indicator of cognitive development degree; the level of activity - as an indicator of the practical development degree, "which is expressed in the ability to translate theoretical knowledge into practice" (Kharitonov, 1999).

The emotionally-evaluative component suggested spiritual development of the high school students: the ability to aesthetically experience, sensually evaluate products of folk art, crafts, women's handicrafts, works of art (emotions, feelings, interests, needs) enabling to awaken aesthetic feelings of motivation to work. In the cognitive component we have included technological, ethnoaesthetic knowledge, skills obtained in the classes of technology, native literature, visual arts (fine arts), the cultures of the native land (CNL), and music, in the pre-core, and core training. In the activity - it is the ability to apply the synthesis of integrative knowledge in practice during the project, arts and crafts activities, to realize creative propensities, a thrifty approach, to do good deeds.

\subsection{The course and description of the experiment}

In the course of the ascertaining experiment the diagnostics of the level of development of a technological culture of the students was carried out. With this objective, a testing was conducted, practical work was accomplished. To define the degree of the technological culture of the subjects of education, we have identified three levels: high ( $3 \mathrm{~b}$.), average (2 b.), low $(1 \mathrm{~b}$.). The analysis of the testing results showed that the main part of the students in both groups had approximately the same results: only 5-9 correct answers for each section of the "Technology" program. Comparing the levels by the components of technological culture, you can see that the performance abilities of students to use technological knowledge and skills in practice were low.

The differences in indicators between the technological knowledge and skills is explained on the one hand, by the desire of students to perform practical work faster and, on the other hand, - by low industriousness, ethnoaesthetic consciousness, poor motivation of cognitive interest in the activities.

The formative stage of the experiment was based on the integrative course "Fundamentals of technological culture: ethnoaesthetic aspect", consisting of the units: "Material culture", "Spiritual culture", "Folk wisdom". The students of the control groups traditionally worked under the program "Technology. Labor training", and in the experimental groups the content of the regional component on the ethnoaesthetic values was realized according to the above indicated units.

\section{Results}

\subsection{The ethnic component of the training/upbringing content}

For full implementation of the ethnic component of the integrative course "Fundamentals of the technological culture: ethnoaesthetic aspect" in the holistic process of creating a technological culture of the subjects of education an integrative program "Ethnoaesthetics: the household book" was developed and implemented, consisting of the following units-modules: "Native literature", "Culture of the native land", "Fine art", "Music", "Technology". For the effective implementation of the experimental work a preparatory work was carried out with technology, native literature, art, and music teachers. They were required to take a creative approach to the use of spiritual, technological content of the national culture, its ethnoaesthetic values in the educational process.

The developed program is as close as possible to the goal of didactics of technology education for schoolchildren, to solving its educational, upbringing, developmental tasks. The integrative course and the program were reviewed by the scientific-methodological Council of the Ministry of education and youth policy of the Chuvash Republic and are permitted for use in educational institutions having the state accreditation and implementing the educational programs.

The integrative program "Ethnoaesthetics: the household book" is intended to organize and conduct classes with 511 grade students. The course includes an introduction of the students to the ethnoaesthetics values of mythological, cosmological, anthropological, technological types of universal culture. The experimental work to validate the effectiveness of the conceptual conditions of using the basics of ethnoaesthetics during the formation of the technological culture was carried out differentially, taking into account sex, age peculiarities of the subjects of continuing education of mid-level, pre-core, and core training. "The technological culture formation. The ethnoaesthetic labor traditions: "Kyl huçi" (the Host), (the Hostess)" modules were integrated into the content of the sections of the program "Technology" where the boys were additionally mastering the technology of clay modeling, art processing of straw, birch bark, basket weaving, molding, house carving, wood turning, designing of musical instruments, modeling architectural constructions, and the girls - technologies of national cookery, embroidery, knitting, designing and modeling clothes.

Synthesis of the artistically-figurative, ethnographic knowledge, gained in the classroom for the above disciplines, 
comes forth as ethnoaesthetic basis for studying the archaic, industrial, modern technologies, organizing the project method for studying in technology classes, in pre-vocational training within the framework of the pre-profile and profile learning, in extracurricular activities.

\subsection{Extra-curricular work of the high school students}

According to the concept of creating a technological culture of the subjects of education on the basis of ethnoaesthetic values an important condition for implementing this process was the involvement of students in extracurricular activities (Nikitin, 2008). Extra-curricular work of each student was reasonably organized both for rest and for self-realization in an interesting matter. Among the traditional forms optional classes were used: discussions, contests, fairs, competitions on technology. Taking into account the cognitive interest of the students, the objects of material and spiritual culture were becoming the objects of researching the ethnoaesthetic values.

The significance of the students' addressing to extracurricular activities is intensified by the fact that in recent years some youth informal groups with chauvinistic, criminal tendencies in the form of "skinhead" movement intensified their activities. In order to distract children from such informal groupings, particular attention was paid to organizing various children's unions, including labor ones.

In the issue of our research, labor unions - are such a form of extracurricular applied activity, where pedagogical problems of creating a technological culture among students using tools of ethnoaesthetic didactics are solved. The function of labor unions is to deepen knowledge in the field of archaic craft technologies, folk crafts, decorative and applied arts, design; self-confidence in their abilities, serving creative interests, inclusion in creative activity. The main activity areas of the labor unions of students are: academic research (activity clubs, scientific societies); culturological (on history, culture, art, philosophy, ethnography issues); artistically-aesthetic (decorative and applied arts).

Work in the traditions of ethnoaesthetics has been viewed as a means of traditional culture of upbringing, orienting children toward the labor lifestyle. This component occupies a fundamental place in the technological culture formation. Therefore, taking into account the principles of the ethnoaesthetic didactics, the following pedagogical conditions are set forth:

- $\quad$ to learn to work, instead of playing in work;

- $\quad$ interesting work is in its benefit, usefulness;

- $\quad$ to work, in order that the results of the labor should please both the student and the consumer;

- rationally organized labor - is a means of self-identification of propensities and abilities;

- the aesthetics of labor - is in expediency, efficiency, in the sense of internal self-satisfaction.

Taking into account the conceptual positions of forming the students' technological culture in the context of the pedagogical components of ethnoaesthetics, to familiarize the students with the basics of small business development in real practice, at comprehensive high school № 49 of Cheboksary in 2000 a school company "Naslediye (Heritage)" was organized. The school company - is an economic and business laboratory, which introduces students to many theoretical laws and economic concepts, such as: demand, supply, variable and fixed costs, performance, et cetera.

Within the school company "Heritage", for complex solutions to issues on the students' technological culture formation, the mini-stock production associations were organized in the experimental grades. Students of 7-8 grades were joined into a company called "Nasledyata (Little Inheritors)"; students of 9 "D" grade created a company "XXI century"; students of 9 "F" grade organized a company "Masterok (A Little Craftsman)"; seniors of 11 "A" grade created a school enterprise "Web" for providing computer services, 11 "B" grade - "the Tree" company for producing children's shovels, 11 "C" grade - a "Hand" company for producing frames, 11 "D" grade - "the Phoenix" company for producing candlesticks. All of these "mini-companies have developed business plans for manufacturing, and production of the folk crafts" (Nikitin, 2012).

The formation of the technological culture of the shareholders in a company was performed according to the traditions of ethnoaesthetics, where as the principle advocated the saying "Above all there is the profit, and the honor - is above the profit". The efficiency of the ethnoaesthetics basics in shaping the technological culture of the shareholders in a school company "Heritage" has been tested in various competitions, festivals, fairs, gatherings, and the academic "Olympiad" competitions in technology.

\subsection{The progress and results of the experiment}

The dynamics of the education subjects' technological culture level formation was determined by means of tests, practical work, and creative training projects. The level indicators were: high ( $50 \mathrm{~b}$. and higher), medium (45-49 b.), low (up to 44 
b.). The comparative characteristics of the levels showed that at the initial (i.) stage the students of the control (CG) and experimental groups $(E G)$ have small differences in the levels of the technological culture components.

To characterize the results of the research the average values of the levels were deduced according to the emotionally-evaluative (motivational): high level in CG (i.) was equal to - 10, $24 \%$, final (f.). - 11,88 \%, EG i. - $11.79 \%$, f. $-19,11 \%$; average: CG i. - 37,71 \%, f. - 41,39\%, EG i. - 36,18 \%, f. - 67,07 \%; low: CG i. - 52,05\%, f. - 46,72, EG i. $-52,03 \%$, f. $-13,82 \%$; the cognitive: high: in CG i. - 10,45 \%, f. $-14,14 \%$, EG i. - 9,35 \%, f. - 31,71 \%; average: CG i. - 56,56 \%, f. - 58,60, EG i. - 56,51 \%, f. - 53,25 \%; low: CG i. - 32,98 \%, f. - 27,25, EG i. - 34,14\%, f. - 15,04 \%; the activity -based: high: in CG i. - $11.96 \%$, f. - 15,05, EG i. - 12,35 \%, f. - 27,37\%; average: CG i. - 48,44 \%, f. - 53,38, EG i. - 48,94\%, f. - 55,53\%; low: CG i. - 39,58\%, f. - 31,55, EG i. - 38,69 \%, f. - 16,09\% components.

It should be noted that in the experimental group at the final stage there increased the number of students, who considered the ethnoaesthetic values as an essential element, encouraging towards the decorative and applied, informative, practical, project, creative, independent activity, the virtue, as important components of forming a technological culture (see fig. 1).

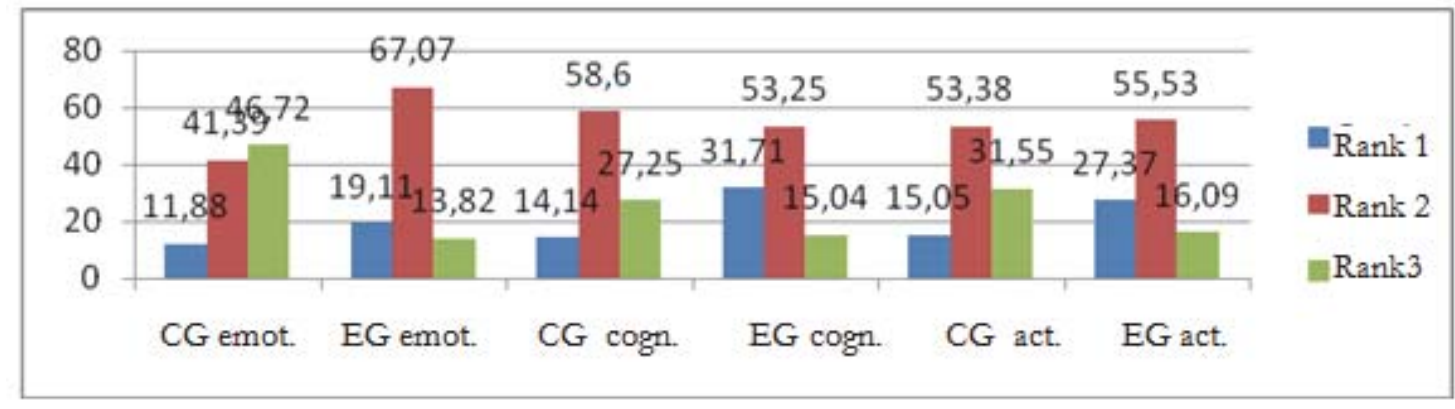

Fig.1. The ratios of the levels of the schoolchildren's technological culture formation based on the ethnoaesthetic values in the CG and EG. The level ranks are: 1 - high, 2 - average, 3 - low

The experimental results show the effectiveness of using the ethnoaesthetic values, which can motivate to form the education subjects' technological culture components.

\section{Discussions}

The concepts of technological (Atutov, 2000), culturological (Krayewski, 2008), ethnocultural (Shpikalova, 2006) education and national educational policy of the Russian Federation became fundamental for the problem of our research. The general theoretical position on the education subjects' technological culture formation is defined relying on the proceedings of (Matyash, 2012), (Pavlova, 2000). The general theoretical contribution to solving the issues on the regional approach to the problem of creating a technological culture has been made by the scholars: (Gilvanov, 2004), (Tigrov, 2000), and others.

This aspect of the conceptual rationale for creating a technological culture of the education subjects based on the ethnoaesthetic values was not considered in previous investigations.

\section{Conclusion}

The proposed conceptual provisions in the article allow highlighting the ethno-social ideas based on the unity of technological (hands), spiritual (heart), and intellectual (mind) components. Covering such subjects as a personality, the society, the educational sphere, the ideas are distributed in the following directions: the first idea (education and personality) - humanization of education on the basis of ethnoaesthetics as a transition from "progressivism" to "childcentrism", to the cult of the students, the cult of "work"; the second idea (education and society) - mutual integration of education into the community and vice versa as the ethnic spiritual and technological components unity in shaping the culture of a person's feelings; the third idea - is a continuous, modular education according to the ethnoaesthetic didactics. 


\section{Recommendations}

The article contents are valuable for technology, native land culture, native language, and music teachers, the instructors of supplementary education, creatively working educators, heads of educational institutions. Of value is the disclosure of the ethnoaesthetic elements on the scientific basis as the life content, the pedagogical tools of socializing the education subjects' technological culture formation process.

\section{References}

Atutov, P. R. (2000). The foundations of studying technology at school. Moscow, 340.

Gilvanov, R. I. (2004). Technological education of students in rural primary schools. PhD Thesis. Sterlitamak, 189.

Kagan, M. S. (1998). Philosophy of the culture. The formation and development. Saint Petersburg, 448.

Kharitonov M.G. (2006). Formation of ethno-pedagogical training of teachers in the activities of the Simbirsk Chuvash school. Cheboksary, 96.

Kharitonov, M.G. (1999). Theory and practice of ethno-pedagogical training of an ethnic elementary school teacher. Thesis. Moscow, 411.

Kharitonov, M.G. (2004). Ethno-pedagogical education of the ethnic school teachers. Cheboksary, 330.

Khotuntsev, Yu.L. (2002). The technologies, the natural scientific worldview. Moscow, 224.

Krayewskiy, V.V. (2008). Methodology of pedagogy. Moscow, 394.

Matyash, N.V. (2012). The innovative pedagogical technologies. Moscow, 160.

Nikitin, G.A. (2008). The concept of forming a technological culture of the learning youth in the context of the ethnoaesthetics' pedagogical component. Cheboksary, 92.

Nikitin, G.A. (2011). Ethnoaesthetics in the practice of forming a technological culture of the high school students. Cheboksary, 364.

Nikitin, G.A. (2012). Formation of the technological culture of the high school students on the basis of ethnoaesthetics: historiography, theory, experience. Cheboksary, 329.

Pavlova, M.B. (2000). The design-approach as the basis of learning (Series "Development of children's creativity through technological projects"). Nizhny Novgorod, 286.

Shpikalova, T.Ya. (2006). The concept of ethno-cultural education. Shuya, 23.

Tigrov,V.V. (2009). Formation of creative capabilities of a student in the process of technological education. PhD Thesis. Tambov, 473.

Volkov, G.N. (2009). The ethno-pedagogical pansophy. Elista, 576. 